NASA Contractor Report 198456

\title{
An Experimental Determination of Losses in a 3-Port Wave Rotor
}

Jack Wilson

NYMA, Inc.

Brook Park, Ohio

February 1996

Prepared for

Lewis Research Center

Under Contract NAS3-27186

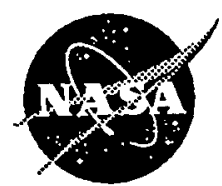

National Aeronautics and

Space Administration 


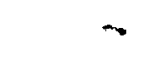




\title{
AN EXPERIMENTAL DETERMINATION OF LOSSES IN A 3-PORT WAVE ROTOR
}

\author{
Jack Wilson \\ NYMA, Inc. \\ Engineering Services Division \\ Brook Park, Ohio 44142, USA
}

\begin{abstract}
Wave rotors, used in a gas turbine topping cycle, offer a potential route to higher specific power and lower specific fuel consumption. In order to exploit this potential properly, it is necessary to have some realistic means of calculating wave rotor performance, taking losses into account, so that wave rotors can be designed for good performance. This in turn requires a knowledge of the loss mechanisms. The experiment reported here was designed as a statistical experiment to identify the losses due to finite passage opening time, friction, and leakage. For simplicity, the experiment used a 3-port, flow divider, wave cycle, but the results should be applicable to other cycles. A $12^{\prime \prime}$ diameter rotor was used, with two different lengths, 9" and 18", and two different passage widths, $0.25^{\prime \prime}$ and $0.54^{\prime \prime}$, in order to vary friction and opening time. To vary leakage, moveable end-walls were provided so that the rotor to end-wall gap could be adjusted. The experiment is described, and the results are presented, together with a parametric fit to the data. The fit shows that there will be an optimum passage width for a given wave rotor, since, as the passage width increases, friction losses decrease, but opening-time losses increase, and vice-versa. Leakage losses can be made small at reasonable gap sizes.
\end{abstract}

\section{NOMENCLATURE}

a speed of sound

B width of a passage on the rotor

$b_{0}, b_{1}, b_{1} \quad$ constants defined in Eq. (19)

$C_{p} \quad$ specific heat at constant pressure

$D_{h} \quad$ hydraulic diameter of passages

$D(x) \quad$ drag on a plate of length $x$

$F \quad$ dimensionless friction parameter, defined in Eq. (4)

$G, G_{p}, G_{w}$ leakage parameters, defined in Eqs. (15), to (17)

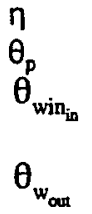

$\theta_{\mathrm{w}}$ height of a passage on the rotor angle of incidence of entering air in the rotor reference frame length of the rotor Mach number in region $\mathbf{j}$ potential number of cycles on the rotor absolute stagnation pressure in region $j$ relative stagnation pressure in region j absolute stagnation temperature in region $\mathbf{j}$ relative stagnation temperature in region j time circumferential velocity of the rotor at the average radius of the passages absolute velocity in region j relative velocity in region $\mathbf{j}$ angle of flow in inlet duct ratio of mass flow in high pressure port to total mass flow ratio of specific heats end-wall to rotor gap spacing end-wall to rotor gap spacing at a port end-wall to rotor gap spacing away from a port boundary layer momentum thickness expansion ratio - ratio of the pressure in the low pressure port to the pressure in a passage just before reaching the low pressure port efficiency angular extent of low pressure port angular extent of low pressure region at iniet endwall

angular extent of low pressure region at exit endwall

$\theta_{w_{\text {in }}}+\theta_{w_{\text {on }}}$ 


$\begin{array}{ll}v & \text { kinematic viscosity } \\ \rho & \text { gas density } \\ \tau & \text { dimensionless opening time, defined in Eq. (1) } \\ \omega & \text { rate of rotation of the rotor }\end{array}$

Subscripts

cav cavity surrounding the rotor into and from which

leakage occurs

j general subscript for any of the three subscripts

below

in inlet port

hi high pressure port

lo low pressure port

pas passage immediately before opening to the low pressure port

\section{INTRODUCTION}

The performance of gas turbine engines can be improved if the combustion temperature can be raised. This is difficult to do because the turbine inlet temperature is limited by material considerations (Peacock and Sadler, 1992). Increased performance can be achieved if the pressure entering the turbine can be increased, while maintaining the rate of heat addition. Thus the combustion step should be configured so as to result in a pressure gain, rather than a pressure loss. Two techniques for achieving this are unsteady combustion (Kentfield, 1995), and use of a wave rotor topping cycle (Meyer, 1947, Zauner et al., 1993, Kentfield, 1995). Because unsteady combustion currently shows only modest pressure gains, the wave rotor approach seems preferable. Calculations show that increases of $20 \%$ in specific power, and reductions in specific fuel consumption of $18 \%$ are possible by using a wave rotor topping cycle (Wilson and Paxson, 1995).

Wave rotors are devices which use unsteady waves to produce steady streams of gas which are at either higher or lower stagnation pressure than the input stream. The rotor itself has a set of passages on its periphery. In the present experiment, which was designed for no exchange of shaft work, the passages are straight, and aligned axially. As the rotor rotates, these passages are alternately exposed to ports at differing pressures. Typically, at the exhaust, or low pressure, port, the passage contains gas at some higher pressure just before the passage rotates into juxtaposition with the port. Exposure to the low port pressure causes an expansion wave to propagate into the passage. Later in the cycle, the passage, now at lower pressure, will be opened to the inlet port, where the gas is at higher pressure, thereby causing a shock wave to be propagated into the passage, increasing the stagnation pressure of the gas. The exact sequence of waves will depend on the cycle employed. Several different cycles are possible, each serving a different function. Examples are three-port cycles, used as flow dividers or equalisers (Kentfield, 1963), four-port cycles, used for superchargers (Jenny and Zumstein, 1982), topping cycles for gas turbine engines (Meyer, 1947, Zauner et al., 1993), and a wave superheater wind-tunnel (Weatherston et al., 1959), and five, and nine port cycles, again intended for use as topping cycles (Thayer et al., 1981). In addition, wave engines for generating shaft work have been developed (Pearson, 1985, Weber, 1995). However, all the cycles have common features, and a study of one should produce results applicable to all cycles, at least in a general sense. For example, all cycles employ an expansion wave, and expanding through too large a pressure ratio leads to losses for any cycle. Obviously, for maximum output, whatever the application, the efficiency of the wave rotor should be as high as possible, i.e. the losses should be minimised. In order to do this, it is necessary to know the source of the losses, and their dependence on controlling parameters. This study is aimed at assessing experimentally the magnitude of various wave rotor losses as a function of the parameters which affect them. This will be achieved by measuring the performance of a wave rotor as various geometrical parameters (passage width, rotor length, and rotor-casing clearance) are varied. The losses are not specific to one cycle, and so any convenient cycle can be used for this study. For simplicity, the three-port flow divider cycle was chosen. In the flow divider, a single inlet flow is split into two outlet flows, one at higher stagnation pressure than the inlet flow, and the other at lower stagnation pressure than the inlet flow. No heat is added, so the apparatus is relatively simple (Fig. 1).

In order to make an experimental study of losses, a wave rotor has been built at NASA Lewis Research Center, operating on the three-port flow divider cycle. This paper contains a brief statement of the philosophy of the experiment, a description of the experiment, and a summary of the measurements made. Finally, results are presented showing that reduction of the rotor-to-wall clearance gap leads to a large improvement in performance, and that friction and opening-time effects also play an important role in the performance.

\section{THE FLOW DIVIDER CYCLE}

The performance of a flow divider is conveniently indicated on a plot of the ratio of high stagnation pressure to inlet stagnation pressure versus the ratio of low stagnation pressure to inlet stagnation pressure, with the mass flow ratio $\beta$ as a parameter (Kentfield, 1969). An upper limit to the performance of the flow divider can be calculated very simply, using what is called the acoustic approximation. In this approximation the following assumptions are made about the flow,

(1) Flow conditions are constant within each region; regions are separated by waves.

(2) Waves are not reflected at ports.

(3) Waves travel at a single speed, which is the average of the wave propagation speeds on either side of the wave, and hence do not spread.

(4) No change in entropy occurs across the waves.

The results of this calculation are shown in Fig. 2(a). This performance, which is called the isentropic performance, is significantly higher than anything that can be achieved in practice, but it does illustrate the features of flow divider performance, i.e., that a large ratio of high pressure to inlet 
pressure is only achieved at a low value of $\beta$. The dotted line terminating the curves of constant mass ratio $\beta$ at the upper left, corresponds to an inlet Mach number of unity. In this approximation, the curves of constant $\beta$ are concave upwards, and maximum performance (i.e. largest high pressure ratio) will be achieved at an inlet Mach number of unity.

A more accurate calculation can be made by using characteristics to evaluate the expansion out of the passages into the low pressure port, and including shock waves in the compression portion of the calculation. This will be called the ideal cycle. The resulting flow divider performance is shown in Fig. 2(b). Now the curves of constant $\beta$ are concave downwards, and the maximum performance (whether defined as pressure rise or efficiency) occurs for an inlet Mach number less than unity. A further, important, difference is where choking occurs. For the isentropic cycle, the inlet Mach number is greater than either of the outlet Mach numbers, and choking would occur at the inlet. In the ideal cycle, for values of $\beta$ of 0.5 and less, reducing the low pressure leads to a Mach number of unity in the low pressure port while the inlet port is still subsonic. In other words, choking occurs at the low pressure port, not the inlet port. Although the ideal performance contains wave losses which are inherent in any real cycle, and so is a better approximation than the isentropic calculation, it can not be achieved in practise since instantaneous opening time and no friction are assumed; conditions which are obviously not attainable.

The isentropic assumption is only valid for weak waves, which is the case for the lower right hand region of Fig. 2, where pressure ratios are close to unity. Comparison of Figs. 2(a) and (b) shows that the isentropic calculation works reasonably well for outlet Mach numbers $M_{10}$ less than about 0.3. The experiments of Kentfield (1969) were entirely within this range, and his curves did not display a pressure ratio maximum. For topping-cycle application, the pressure ratio should be as large as possible, and so one consideration in the present experiment was to operate the wave rotor under conditions for which the acoustic approximation would not be valid, and observe whether there is indeed a maximum in the performance. Consequently, a design expansion ratio of 0.33 was chosen, corresponding to a Mach number of the expanded flow of 0.85 . The expansion ratio is the ratio of the pressure in the low pressure port to the pressure in a rotor passage just before it is opened to the low pressure port. This ratio determines the Mach number of the flow in the low pressure port. For an expansion ratio of 0.33 , the expansion wave exhibits significant spreading, as can be seen in the $x$-t diagram of the cycle shown in Fig. 3.

\section{LOSS MECHANISMS}

Although several wave rotors have been built in the past,only two studies of losses appear to have been reported, namely theoretical estimates of losses by Hoerler (1969) for the Comprex@, and by Kentfield (1963) for the flow divider. Kentfield gives the following losses as being in order of decreasing importance;

\section{Basic wave effects \\ 2. Cell width, i.e. opening time effects \\ 3. Wall friction, passage entry and exit losses \\ 4. Leakage}

Hoerler calculated losses for the rotor itself, as percentage losses in efficiency for an experimental Comprex, and also for a hypothetical optimized Comprex. The results are given in Table 1. In addition, there are losses for ducts and stators external to the rotor. Hoerler states that leakage can dominate all other rotor losses, particularly for small machines, which is just the opposite of the conclusions by Kentfield. This disagreement reflects the different geometries of the two machines considered, as will be explained below.

It will be assumed that the friction, opening-time, and leakage losses, will scale with one predominant parameter for each loss. The derivation of the parameter for each of these losses, plus the estimation of other losses will be outlined below.

\section{Basic Wave Effects}

Basic wave effects are the losses due to shock waves and spreading of expansion waves, which cause the difference in performance between the ideal cycle and the isentropic cycle. A real cycle can have shock waves instead of compression waves. There is a loss of stagnation pressure across a shock wave, leading to a reduction in performance. Expansion waves spread in space as they propagate, resulting in nonuniform velocities in the exit ports. Mixing of the nonuniform velocity distribution to form a uniform distribution causes a stagnation pressure loss. These losses are unavoidable in a real device. The losses due to these effects depend on $\beta$ and $\varepsilon$, and are readily calculable if the timing is correct, i.e. if the ports open and close at the appropriate times as determined by the arrival, or launching, of waves. For maximum performance, the timing will be different for each value of $\beta$ and $\varepsilon$ considered. An actual device will usually have timing fixed for one set of conditions, and operation off-design will create extra waves, causing additional losses. This can be handled computationally using a onedimensional CFD code for wave rotor cycles (Paxson, 1995). The ideal cycle performance can not be measured directly in an experiment. It can be determined from experimental results by measuring performance as a function of the other losses, and extrapolating them to zero.

\section{Finite Passage Opening Time}

Since the passages have a finite width, there is a finite time taken for a passage to rotate past the leading or trailing edge of a port, and become fully open or closed. In the case of an inlet port, for which instantaneous opening of the passage would cause a shock wave to propagate down the passage, a finite opening time will result in a compression wave, which will steepen into a shock as it travels down the passage. The degree to which it steepens depends on the ratio of the opening time to the time taken by the wave to travel the length of the passage. Thus the relevant non-dimensional parameter is 


$$
\tau=\frac{\text { Passage Opening Time }}{\text { Wave Travel Time }}=\left(\frac{B}{U}\right)\left(\frac{a}{L}\right)
$$

The speed of sound, a, will vary depending on which region of the cycle is being considered. For simplicity of definition, the inlet stagnation value will be used. Note that for any particular cycle, the rotor velocity $U$ will be inversely proportional to the axial length of the passage $L$, and hence $\tau$ is determined mainly by the value of the passage width, $B$. In addition to the effect on wave steepening, which may be advantageous, finite opening time will result in deleterious throttling losses when the passage is partially open. Further, finite opening time will create a gradual rise in velocity at the outlet ports, and finite closing time will create a gradual reduction in velocity at the outlet ports. The resulting non-uniform velocity distribution will result in a drop in stagnation pressure when it is mixed out to a uniform value downstream. Clearly this loss will increase as $\tau$ increases.

\section{Friction}

Although the rotor passages are long and slender, their maximum length to width ratio is less than the entrance length for pipes. Thus the flow can be considered to have a boundary layer. This is confirmed by measurements of the radial velocity distribution in the high pressure port, showing a uniform velocity over the central $70 \%$ of the passage, and two-dimensional calculations of the flow in the entrance and high pressure ports of the experimental geometry (Welch and Chima, 1993) also showing a relatively small boundary layer. The flow in a passage open to the low pressure port can be thought of as flow over a flat plate, with the leading edge of the "plate" being the location of the leading edge of the expansion wave. A friction parameter can then be defined as the ratio of the drag force due to the flat plate to the product of inertial pressure and flow area, i.e.

$$
F=D(x) \frac{1}{2} \rho W^{2} B H
$$

The drag is related to the boundary layer momentum thickness at the end of the passage (Schlichting, 1979). Following Hoerler (1969), the boundary layer was assumed turbulent. With this assumption, the boundary layer momentum thickness is given by (Schlichting, 1979)

$$
\delta_{2}(x)=0.036 x(W x / v)^{-0.2}
$$

The length of the boundary layer varies linearly with time as the expansion moves into the passage. By averaging over the time that the port is open, the friction parameter becomes

$$
F=0.32 \frac{L}{D_{h}}\left[\frac{L W}{V}\right]^{-0.2}
$$

This parameter will be taken as representative of the effect of friction on the cycle as a whole. The dominant factor in the friction parameter is $L / D_{h}$.

\section{Heat Transfer}

Since it was not possible to measure heat transfer due to the lack of a sensor with a sufficiently rapid response rate, there seemed little point in making a separate assessment for heat transfer. It will depend on the same parameter as friction, so the two losses were simply incorporated together as one loss.

\section{Circumferential Velocity Loss}

If the angle $\alpha$ of the inlet duct is correct, the inlet flow will enter the passages smoothly at zero incidence in the relative frame (Fig. 4). This will only occur at design conditions (and even then, only if the design is correct!). Off-design, the flow will be at some angle of incidence, $i$, to the passage side walls, and work will be done on the gas, or extracted from it. This is equivalent to a flat plate compressor. The work done on the gas follows from the Euler equation for turbomachinery;

$$
C_{p} \Delta T=U\left(U-V_{\text {in }} \sin \alpha\right)
$$

in which the stagnation temperature rise $\Delta T$ is defined as,

$$
\Delta T=\beta T_{H i}+(1-\beta) T_{L O}-T_{\text {in }}
$$

Measurements of motor power in some runs showed that the temperature rise could be as high as $20^{\circ} \mathrm{R}$, corresponding to a motor power of about $10 \mathrm{HP}$. Both the velocity $V_{\text {in }}$ and the flow angle $\alpha$ vary across the inlet port, and an overall value of the work done must be evaluated by integration. Depending on the angle of incidence, the relative stagnation pressure entering the rotor may be either greater or less than the absolute input stagnation pressure.

The wave action takes place entirely within the rotor, producing changes of pressure in the relative frame. However, the actual performance of a device is measured in the absolute frame, and will be affected by the rotor rotational speed. The experiments are run at three different rotational speeds, and so should be compared in the relative frame to remove the effect of the differing rotational speeds. Also, the ideal performance, as given above, is in the relative frame (since no correction for rotation was made, which is equivalent to assuming that the rotational velocity is zero). Thus it is necessary to correct the 
observed absolute results to the relative frame. The flows leaving the rotor will have relative stagnation temperatures of

$$
\operatorname{Tr}_{\mathrm{j}}=\mathrm{T}_{\mathrm{j}}-\mathrm{U}^{2} / 2 \mathrm{C}_{\mathrm{p}}
$$

and hence the ratio of output relative to absolute stagnation pressure will be

$$
\frac{P r_{j}}{P j}=\left[\frac{T r_{j}}{T_{i}}\right]^{V /(Y-1)}
$$

In general, the relative pressure gain, $\mathrm{Pr}_{h \mathrm{~h}} / \mathrm{Pr}_{\mathrm{in}}$, and the relative pressure loss, $\mathrm{Pr}_{10} / \mathrm{Pr}_{i n}$, will be greater than the absolute values, so that this effect is equivalent to a loss. However for the flow divider (though not necessarily for other cycles), this effect is fairly small.

\section{Leakage}

Leakage can take place radially from the passage to the casing if the passage is at high pressure, or from the casing to the passage if the passage is at low pressure. The result will be a "short-circuiting" from high pressure to low, leading to reduced performance. In addition, circumferential leakage is possible, from passage to passage. The pressure difference driving circumferential leakage is small except when a wave has reached the end of a passage. Thus circumferential leakage is likely to be small. For radial leakage, the rate of mass leakage will be proportional to the area available for leakage, which is $28 \mathrm{~B}$ at each end of a passage. The leakage will be into the passage while it is in a region of low pressure. From Fig. 3 , the low pressure region on the inlet side extends over an angle $\theta_{w_{i n}}$, and on the outlet side, the low pressure region is the low pressure port, of extent $\theta_{p}$, and the region between the low pressure port and the high pressure port, of extent $\theta_{w_{\text {our }}}$. Thus the time spent at low pressure is

$$
t=\theta_{w_{i n}} / \omega
$$

at the inlet side of the wave rotor, and

$$
t=\theta_{p} / \omega+\theta_{w_{\text {out }}} / \omega
$$

at the outlet side of the wave rotor. The amount of mass leaking into a passage will be

$$
\text { mass } \sim \rho_{c a v} 2 B\left(\delta_{w} \theta_{w_{i n}}+\delta_{p} \theta_{p}+\delta_{w} \theta_{w_{o v}}\right) / \omega
$$

Defining a leakage parameter as the ratio of the mass leakage to the mass in a passage before it reaches the low pressure port, i.e. $\rho_{\text {pas }}$ BHL, the leakage parameter becomes, if $\rho_{\text {s }}$ is assumed equal to $\rho_{\text {cav }}$.

$$
G \sim 2\left(\delta_{p} \theta_{p}+\delta_{w} \theta_{w}\right) / \omega H L
$$

For operation of a specific wave rotor, $\omega L$ is a constant. For convenience, relative values of $\theta_{p}$, and $\theta_{w}$, can be used such that

$$
\theta_{p}+\theta_{w}=2
$$

and the proportionality constant chosen so that the leakage parameter is defined as;

$$
G=\left(\delta_{p} \theta_{p}+\delta_{w} \theta_{w}\right) / H
$$

Then if the leakage gaps are equal, i.e. $\delta_{\rho}=\delta_{w}=\delta$, this reduces to

$$
G=2 \delta / H
$$

Based on this derivation, one would expect that the leakage in the Comprex studied by Hoerler (1969), would be similar to that in the experiments of Kentfield (1963), since the ratio $2 \delta / \mathrm{H}$ was virtually the same for both devices, but Hoerler claimed leakage was important, whereas Kentfield said that it was not. However, the two devices operated on quite different cycles, and whereas the experiment of Kentfield used a similar cycle to that of the present experiment, the Comprex cycle was different. In the Comprex, which used a four-port cycle, the inlet port and exhaust port were at approximately the same pressure, which was significantly lower than the two high pressure ports. The cavity was therefore likely to be at some intermediate pressure. This means that the assumption above that $p_{\text {cav }}=p_{\text {pas }}$, is probably not correct for the Comprex, and also there would be leakage into the inlet port. Both of these effects would lead to more leakage. An additional difference was the relative extent of the low pressure regions, with more of it in a port region for the Comprex. It thus seemed important to ascertain in the present experiment whether leakage at a wall is more, or less, important than leakage at a port. In order to do this, the wall gap and port gap were varied independently. Thus separate port and wall leakage parameters were defined, i.e. 


$$
\begin{aligned}
& G_{p}=\delta_{p} \theta_{p} / H \\
& G_{w}=\delta_{w} \theta_{w} / H
\end{aligned}
$$

Relative values of $\theta_{p}=0.71$ and $\theta_{w}=1.29$ were used, so that when the wall and port gaps are equal, the total leakage parameter,

$$
G=G_{p}+G_{w}=(0.71 \delta+1.29 \delta) / H=2 \delta / H
$$

in agreement with Eq. (15) above.

\section{Entrance and Exit Losses}

The wall between the passages has a finite thickness. There is consequently an area change between flow in the ducts, and flow in the passages. The squared ends of the walls will present an obstruction to the flow on entering, and a drag on leaving, leading to stagnation pressure losses. This effect was calculated by assuming the leading edge is at the entering stagnation pressure, and the trailing edge is at the downstream static pressure. The resulting force on the flow is included in the momentum equation, which is then solved with the continuity and energy equations to give the downstream stagnation pressure. The losses in stagnation pressure are less than $2 \%$ for the narrow passages, and less than $1 \%$ for the wide passages.

\section{EXPERIMENTAL DESIGN}

In order to be able to obtain experimental values of the losses due to opening time, friction and port and wall leakage, the parameters $\tau, F, G_{p}$ and $G_{w}$ must be varied. An efficient way to formulate an experiment to obtain empirical fits to data when there are three or more variable parameters is the BoxBehnken scheme (Box and Behnken, 1960). This scheme is illustrated for three variables in Fig. 5. Imagine a box, each side of which extends from the minimum value of the corresponding variable to the maximum value of the variable. Experimental readings are taken at the points indicated in the middle of each side, together with three replicate points at the center of the box. It is then possible to fit the results with a second-degree polynomial. For example, if the measured variable is the efficiency $\eta$, and the independent variables are $\tau, F$, and $G$, then the fit will be of the form

$$
\begin{aligned}
\eta=b_{0}+b_{1} \tau+b_{2} F+b_{3} G+b_{11} \tau^{2}+b_{22} F^{2} & +b_{33} G^{2}+b_{12} \tau F \\
& +b_{13} \tau G+b_{23} F G
\end{aligned}
$$

where the constants $b_{0}, b_{\|}$and $b_{\|}$are determined from the experimental measurements. The replication of the center point provides an estimate of the experimental error. The scheme for four variables is equivalent, but harder to illustrate since drawing a four-dimensional box is rather difficult! The set of runs that must be made in order to evaluate the constants was determined using commercial software (Seshadri and Deming, 1990), and is listed in Table 2. The same software was also used to determine the constants from the experimental data.

The present wave rotor experiment was formulated as a four variable design, with $\tau, F, G_{p}$, and $G_{w}$ as the independent variables. The dependent variable, or response, was taken to be the efficiency, which has been defined for a flow divider (Kenttield, 1969) as

$$
\eta=\frac{\beta}{(1-\beta)}\left[\frac{\left(P_{h /} / P_{\text {in }}\right)^{(v-1) / V_{-1}}}{1-\left(P_{\text {ld }} / P_{\text {in }}\right)^{(v-1) / \gamma}}\right]
$$

In designing the experiment, the actual rotor dimensions had to be determined. A review of the literature showed that the geometry had differed significantly for rotors built in the past, sometimes with no indication of the value of the end-wall to rotor gaps. The details of several past rotors are given in Table 3. The non-dimensional opening time $\tau$ has varied over a range of 0.1 to 0.35 . The major component of the friction parameter, namely the ratio $L D_{n}$, has varied between 3.7 and 84 . Finally, the leakage parameter $G$ (previous workers have not differentiated between $G_{p}$ and $G_{w}$ ), has varied from 0.005 to 0.017 . The objective in designing this experiment was to cover as much of this range as possible. In order to do this, the actual experiment consisted of two different rotors, both $12^{\prime \prime}$ in diameter, but one $18^{\prime \prime}$ long, the other $9^{\prime \prime}$ long. Both were built with passages $0.25^{\prime \prime}$ wide, and $0.4^{\prime \prime}$ high, with 120 passages per rotor. After a series of runs at $0.25^{\prime \prime}$ passage width, every other wall was removed, and another series of runs was made at approximately twice the passage width. Ducts were designed for operation at $n=1.5$ for both the $9^{\prime \prime}$ and $18^{\prime \prime}$ long rotors. Adding a different set of ducts for operation at $n=3$ with the $18^{4}$ rotor, provided a combination giving three values of $\tau$, and three values of $L / D_{n}$, covering the range 20 to 58 , and hence three values of $F$. The value of $n=1.5$, rather than $n=1$, was used to provide a long region between closing of the high pressure port, and opening of the low pressure port, to allow any remaining waves to die out, and give the uniformity prior to opening the low pressure port that was assumed in calculating the cycle. In fact, only one actual cycle was used; what is meant by $n=1.5$, and $n=3$, is the number of cycles there could be per revolution at the timing used for the one cycle. In order to vary the port leakage gaps, the ports were built as inserts, supported on a flange. Placing shims under the flange permitted variation of the rotor to port gaps. The rotor to wall gap was varied by providing moveable end-walls at each end, consisting of disks, which could move axially. Springs at three locations pushed the disks away from the rotor, and three screws forced the disks towards the rotor. Adjustment of the screws gave the desired gap spacing. The minimum spacing that could be used safely was 
$0.005^{\prime \prime}$, larger than had been hoped for. This gave a value of $\mathbf{G}=0.025$, which was greater than the values used by other workers due to the small passage height of the present experiment.

The experimental results were measured in the absolute frame of reference. Since in the experiment, different rotational speeds, and different ratios of wall thickness to passage width were used, the circumferential loss and entrance and exit losses were not the same from run to run. Consequently the absolute pressure ratios were converted to the relative frame, and corrected for entrance and exit losses. The differences between the corrected pressure ratios as the geometry is varied should then be the differences due to the variation in opening time, frictional, and leakage losses.

A photograph of the apparatus, with the $18^{\text {n }}$ rotor in place, is shown in Fig. 6.

\section{EXPERIMENTAL MEASUREMENTS}

The efficiency of the flow divider (Eq. 20) is determined by the ratios of $P_{h i} / P_{\text {in }}$ and $P_{10} / P_{\text {in }}$ at a particular value of $\beta$. Higher values of both ratios correspond to higher efficiency. The necessary measurements are therefore the mass flows in each port, and the stagnation pressures of the inlet, high pressure, and low pressure flows. The mass flows were measured with standard orifice meters. The ports are obviously sections of an annulus. A transition piece in front of the inlet port took the flow in the inlet pipe, and converted it to the port shape, accelerating the flow in the process, as well as bringing it onto the rotor at the correct angle. Immediately upstream of the transition piece, but downstream from the orifice, was a diagnostic spool, with three wall static taps, five pitot tubes, and a thermocouple. The inlet stagnation pressure and temperature were determined by measurements at this spool. Similarly, the output ports had transition pieces to take the flow from the port shape back to round, and which also acted as diffusers. The downstream area of these diffusers was fixed by the exhaust pipe diameter. With the diffuser area ratio determined, the length was chosen to give maximum diffuser efficiency, using the diffuser performance curves of Mattingly et al. (1987). A diagnostic spool was placed immediately at the exit of each diffuser, with the intention of using the measurements to evaluate exit stagnation pressures. However, the velocity distribution was found to be very non-uniform, and it was not clear whether the resulting stagnation pressure would be reliable. In addition, measurements made at the ports were used to calculate a stagnation pressure. There were 5 static pressure taps on the top and bottom of each port, and four pitot tube installations. The pitot installations carried either a rake of 5 pitot tubes to determine radial velocity distribution, or a tube-type combination probe (Glawe and Krause, 1974), to determine center-line velocity and direction. In the high pressure port, velocities are low, and relatively uniform, and an average of the individual port stagnation pressure measurements was taken as the port stagnation pressure. In the low pressure port, the velocity distribution is very non-uniform, both radially, and circumferentially. The measurements were used to create a circumferential velocity distribution, and also, by using a rake probe, to create a radial velocity distribution. These distributions were used to create mass, momentum, and energy integrals for a mixing calculation (Foa, 1960), from which the stagnation pressure for a uniform downstream velocity was evaluated, and used as the low pressure port stagnation pressure. The pressure measurements were steady state. For some runs, a dynamic pressure transducer was installed 4" downstream of the low pressure port. The signal from this transducer was a sine wave at the passage passing frequency, with a peak to peak value of 0.5 percent of the steady state pressure. Thus the pressures were essentially steady state.

All steady state pressure measurements were recorded through an electronically scanned pressure (ESP) measurement system. The pressure measuring system automatically self-calibrates every 20 minutes to maintain a $0.1 \%$ accuracy. The ESP system communicates through an institute of Electrical and Electronics Engineers 488 interface to a state of the art, real time data acquisition system designed at NASA Lewis (Fronek et al., 1987). The data system was designed for small to medium sized aeronautics facilities, most of which are currently testing rotating machinery. The system acquires data, converts it to engineering units, computes test dependant performance calculations, and displays the information in alphanumeric or graphical form. The cycle time is one second.

Control of the wave rotor flows was by a butterfly valve in each leg. The supply pressure was around 55 psia. The inlet valve was adjusted to throttle this supply pressure down to the desired inlet stagnation pressure, usually $30 \mathrm{psia}$. The expansion ratio was set by the low pressure valve, based on a low pressure port static pressure reading, and a pressure tap in the endwall giving the passage pressure just before opening to the low pressure port. The high pressure valve controlled the mass ratio $\beta$, based on the input and high pressure orifice mass flow readings. The rotor was tumed by a variable speed electric motor with a constant speed control. An independent measurement of the rotor speed was also made.

\section{RESULTS}

For the statistical experiment, runs were made at a nominally constant value of $\beta=0.37$, mostly at an input stagnation pressure of 30 psia, varying $\varepsilon$ from 0.33 to 0.8 , unless the full range was not accessible. Because it was not possible to achieve $\beta=0.37$ exactly on every run, runs were also made at a nominal $\beta=0.36$, and $\beta=0.38$. From these extra runs, a local value of the derivatives of $P_{h} / P_{\text {in }}$ an $P_{10} / P_{\text {in }}$ with respect to $\beta$ could be calculated, and used to correct the runs at nominal $\beta=0.37$ to values corresponding to exactly $\beta=0.37$. In addition, corrections for conversion to the relative frame, and for entrance and exit losses were made. Each run was duplicated, and then the average of the corrected values of $P_{h} / P_{i n}$ and $P_{10} / P_{\text {in }}$ for the two runs was taken as the final result.

The results were plotted as $P_{h} / P_{i n}$ versus $P_{10} / P_{i n}$. A sample of the results showing performance changes for the different rotors with both port and wall gaps set equal to $0.010^{\prime \prime}$, is given in Fig. 7. All these runs were made at an inlet stagnation pres- 
sure of 30 psia. The runs made with the $18^{\prime \prime}$ rotor at $n=3$ have a larger opening time than the runs with $n=1.5$, but the same value of friction factor. Thus it is seen that increasing the opening time reduces performance. Runs with the wider passages are superior in performance to runs made with the narrow passages. The runs with the wider passages have a larger opening time, but lower friction factor than the runs with the narrow passages. For these runs then, reduction in friction is more beneficial than the increase in opening time is deleterious. This is more evident for the runs with the $18^{\prime \prime}$ rotor than it is for the runs with the $9^{\prime \prime}$ rotor, indicating that friction is becoming less important for the shorter rotor.

Results obtained with the $18^{\prime \prime}$ rotor at three different gap spacings are shown in Fig. 8. The three runs at a gap spacing of $0.010^{\prime \prime}$ are the replicated runs at the center point, giving an idea of the experimental error due to lack of reproducibility of gap setting. It is clearly much less than the change in performance caused by a gap change of $0.005^{\prime \prime}$, so the observed effect is real. The variation at a fixed gap setting is of the order of 0.003 , much less than the error due to gap setting, showing that irreproducibility of gap setting is the major source of experimental error. There is a significant increase in performance as the gap spacing is reduced.

\section{EVALUATION OF THE RESULTS}

At each value of expansion ratio, the corrected values of $P_{n} / P_{i n}$ and $P_{b o} / P_{i n}$ were used to calculate an efficiency, and this was entered into the statistical program. The program then evaluated the values of $b_{0}, b_{1}$ and $b_{H}$, and provided the confidence estimate of each value. Values with low confidence were dropped from the model. For example, at an expansion ratio of 0.6, (which is intermediate between the maximum pressure ratio at an expansion ratio of 0.55 , and the maximum efficiency at an expansion ratio of 0.65 ), the final model was

$$
\eta=b_{0}+b_{3} G_{p}+b_{4} G_{w}+b_{11} \tau^{2}+b_{22} F^{2}+b_{12} \tau F
$$

The values of the constants are given in Table 4. This remarkably simple model shows that the efficiency decreases linearly with the end-wall to rotor gap spacing. Moreover, since $\left|b_{3}\right|$ is larger than $\mathrm{lb}_{4} \mathrm{l}$, when the relations in Eqs. (16) and 17) are entered for the leakage parameters, the efficiency is almost equally sensitive to port gap and wall gap,

$$
\eta=0.42-0.84 \delta_{\rho} / H-0.72 \delta_{w} / H-1.3 \tau^{2}-1.74 F^{2}+0.70 \tau F
$$

The linear relationship between efficiency and leakage parameter is confirmed in Fig. 9, showing efficiency versus leakage parameter for the $9^{\prime \prime}$ rotor. This result indicates that values of leakage parameter of 0.005 or less are desireable for good efficiency.

The model can be used to extrapolate the results to zero leakage parameter. A contour plot of efficiency at no leakage, as a function of opening time and friction factor, derived with the full model, is given in Fig. 10. It will be seen that there is a ridge of high efficiency sloping away from a maximum at the origin, and falling off rapidly along the axes. This result can be used to derive an optimum passage width for a given wave rotor. Assume that the rotor length and passage height are fixed, and that the ratio of $\mathrm{B} / \mathrm{H}$ is 2 at a friction factor of 0.4 . As the value of $B$ is decreased, the opening time gets less, and the friction factor increases. As $B$ is increased, the opposite is true. Thus the locus of points along a curve of constant rotor length, but varying passage width is approximately a hyperbola. The exact curve is plotted in Fig. 10, labelled " $L=$ constant". This curve is tangent to the contour of efficiency $=0.48$ at the point $F=0.42, \tau=0.185$. As will be seen, this is also the point of highest efficiency for this curve, and therefore the passage width appropriate to this point is the optimum for this rotor. Examination of the other contour plots indicates that the optimum for different length rotors will lie along the line

$$
F=2.25 \tau
$$

The contour plot shows that the maximum efficiency is at the origin, i.e. as small a value of friction factor and opening time as possible. This may not be the case in reality, for two reasons. First, the model is strictly valid only in the space covered by the experiment, which was the region $\tau=0.085$ to $0.37, F=0.37$ to 1.12. The origin is outside this region, and extrapolation of the model to the origin may give erroneous results. Secondly, the results have been referred to the relative frame. As one gets closer to the origin, the rotor length gets smaller, and the rotor speed goes up. This can result in the absolute performance being significantly below the relative performance, so that a longer, slower, rotor may have better performance. Such an effect was found for four-port wave rotors in an optimization study (Wilson and Paxson, 1995). If the extrapolation to the origin is correct, the result should be the efficiency calculated from the ideal cycie, or rather, since an expansion ratio of 0.6 is off-design, the efficiency calculated with the one-dimensional model of Paxson (1995). Extrapolation with the full model gave an efficiency of 0.54 , compared with an efficiency of 0.56 calculated with the one-dimensional model.

\section{CONCLUSIONS}

Operation of a three port wave rotor has shown that, at a constant value of $\beta=0.37$, the maximum pressure ratio occurs at an expansion ratio 0.55 , and the maximum efficiency at an expansion ratio of 0.65 . These expansion ratios are significantly higher than the lowest possible expansion ratio. The loss of efficiency in a wave rotor due to leakage has been demonstrated experimentally to be linear in the end-wall to rotor gap spacing. Values of the leakage parameter $\mathrm{G}=2 \delta / \mathrm{H}$ less than 0.005 are required for good efficiency. Friction and opening time losses cause the efficiency to decrease with the square of the friction factor, and the square of the opening time, with an offsetting term increasing as the product of the friction factor and the opening time. Optimum wave rotor efficiency will be obtained if the rotor is designed so that the friction factor is 2.25 times the dimensionless opening time. 


\section{ACKNOWLEDGMENTS}

The author is grateful to D. Paxson and G. Welch for many fruitful discussions Special thanks go to C. Horn III, T.J. Doerberling, L.J. Bellisario, and P. Adams whose careful work in the laboratory made this work possible, to D. Fronek for taking care of all the details of instrumentation, and $\mathrm{H}$. Weaver for operational support.

\section{REFERENCES}

Box, G.E.P., and Behnken, D.W., 1960, "Some New ThreeLevel Designs for the Study of Quantitative Variables," Technometrics, Vol. 2, pp. 455-75.

Foa, J.V., 1960, "Elements of Flight Propulsion," John Wiley and Sons, New York, NY, pp. 161-166.

Fronek, D.L., Setter, R.N., Smalley, R.R., and Blumenthal, P.Z., 1987 "A Distributed Data Acquisition System for Aeronautics Test Facilities," NASA TM-88961.

Glawe, G.E., and Krause, L.N., 1974, "Miniature Probes for use in Gas Turbine Testing," NASA TM X-71638.

Hoerler, H.U., 1969, "Abschatzung der Verluste in instationargasdynamischen Kanaltrommel-Drucktauschern," Doctoral Dissertation Number 4402, Eidgenossische Technische Hochschule, Zurich, Switzerland.

Jenny, E., and Zumstein, B., 1982, "Pressure Wave Supercharging of Passenger Car Diesel Engines", CP C44/82, The Institution of Mechanical Engineers, London, England, pp. 129-141.

Kentfield, J.A.C., 1969, "The Performance of Pressure Exchange Dividers and Equalisers", Journal of Basic Engineering, pp. 361-370.

Kentfield, J.A.C., 1995, "On the Feasibility of Gas-Turbine Pressure-Gain Combustors", International Journal of Turbo and Jet Engines, 12, pp. 29-36.

Mattingly, J.D., Heiser, W.H., and Daley, D.H., 1987, "Aircraft Engine Design", AlAA Education Series, American Institute of Aeronautics and Astronautics, Washington, DC.

Meyer, A., 1947, "Recent Developments in Gas Turbines", Mechanical Engineering, Vol. 69, pp. 273-277.

Paxson, D.E., 1995, "Comparison between numerically modelled and experimentally measured Wave-Roto $r$ Loss
Mechanisms", Journal of Propulsion and Power, Vol. 11, No. 5, pp. 908-914.

Peacock, N.J., and Sadler, J.H.R., 1992, "Advanced Propulsion Systems for Large Subsonic Transports", Journal of Propulsion and Power, Vo.l 8, No. 3, pp. 703-708.

Pearson, R.D., 1985, "A Gas Wave-Turbine Engine which developed 35 H.P., and performed over a 6:1 Speed Range", Proceedings of the 1985 ONR/NAVAIR Wave Rotor Research and Technology Workshop, Shreeve, R.P. and Mathur, A. Editors, Report NPS-67-85-008, Naval Postgraduate School, Monterey, CA pp. 125-170.

Schlichting, H., 1979, "Boundary-Layer Theory", McGraw-Hill Book Company, New York, NY, p. 637.

Seshadri, S. and Deming, S.N., 1990, "Interactive Computer Programs for Using Three- and Four-Factor Box-Behnken Designs in Research, Development, and Manufacturing", Statistical Programs, Houston, TX.

Thayer III, W.J., Taussig, R.T., Zumdieck, J.F., Vaidyanathan, T.S., and Christiansen, W.C., 1981, "Energy Exchanger Performance and Power Cycle Evaluation: Experiments and Analysis", Final Report by MSNW to DOE under Contract AC06-78ER01084.

Weatherston, R.C., Smith, W.E., Russo, A.L., and Marrone, P.V., 1959, "Gasdynamics of a Wave Superheater Facility for Hypersonic Research and Development", CAL Report No. AD118-A-1.

Weber, H.E., 1995, "Shock Wave Engine Design", John Wiley and Sons, Inc, New York, NY.

Welch, G.E., and Chima, R.V., 1993, "Two-Dimensional CFD Modeling of Wave Rotor Flow Dynamics", NASA TM-106261.

Wilson, J., and Paxson, D.E., 1995, "Optimization of Wave Rotors for Use as Gas Turbine Engine Topping Cycles", SAE Paper No. 951411, Aerospace Atlantic Conference, Dayton, Ohio. Also NASA TM-106951.

Zauner, E., Chyou, Y-P., Walraven, F., and Althaus, R., 1993, "Gas Turbine Topping Stage based on Energy Exchangers: Process and Performance", ASME Paper ASME93-GT-58, Gas Turbine and Aeroengine Congress, Cincinnatti, Ohio. 
TABLE 1.-LOSS OF EFFICIENCY IN A COMPREX®

\begin{tabular}{|l|c|c|}
\hline \multicolumn{1}{|c|}{ Source of loss } & $\begin{array}{c}\text { Loss in experimental } \\
\text { COMPREX }\end{array}$ & $\begin{array}{c}\text { Loss in optimized } \\
\text { COMPREX }\end{array}$ \\
\hline Shocks and Fans & $4.5 \%$ & $3.3 \%$ \\
\hline Passage opening/closing & $4.1 \%$ & $4.2 \%$ \\
\hline Friction (turbulent) & $7.2 \%$ & $2.1 \%$ \\
\hline Heat transfer & $3.3 \%$ & $2.1 \%$ \\
\hline Rotational velocity & $4.2 \%$ & $2.0 \%$ \\
\hline Leakage & $10.1 \%$ & $1.1 \%$ \\
\hline Mechanical & $2.3 \%$ & $0.1 \%$ \\
\hline Interface mixing & 0 & 0 \\
\hline Total & $35.7 \%$ & $14.9 \%$ \\
\hline
\end{tabular}

TABLE 2.-SET OF RUNS FOR THE STATISTICAL EXPERIMENT

\begin{tabular}{|c|c|c|c|c|c|c|c|}
\hline $\begin{array}{c}\text { Run } \\
\text { number }\end{array}$ & $\begin{array}{l}\text { Rotor } \\
\text { length, } \\
\text { in. }\end{array}$ & $\begin{array}{c}\text { Passage } \\
\text { width, } \\
\text { in. }\end{array}$ & $n$ & RPM & $\begin{array}{l}\text { Port } \\
\text { gap, } \\
\text { in. }\end{array}$ & $\begin{array}{l}\text { Wall } \\
\text { gap, } \\
\text { in. }\end{array}$ & P1 \\
\hline 1 & 18 & 0.25 & 1.5 & 3700 & 0.010 & 0.010 & 30 \\
\hline $\begin{array}{l}2 \\
3 \\
4 \\
5\end{array}$ & 18 & 0.25 & $i^{3.0}$ & 1850 & $\begin{array}{l}0.005 \\
0.015 \\
0.010 \\
0.010\end{array}$ & $\begin{array}{l}0.010 \\
0.010 \\
0.005 \\
0.015\end{array}$ & 30 \\
\hline $\begin{array}{l}6 \\
7 \\
8 \\
9 \\
10\end{array}$ & $\begin{array}{l}9 \\
1\end{array}$ & 0.25 & 1 & $\begin{array}{c}7400 \\
1\end{array}$ & $\begin{array}{l}0.010 \\
0.010 \\
0.010 \\
0.005 \\
0.015\end{array}$ & $\begin{array}{l}0.010 \\
0.005 \\
0.015 \\
0.010 \\
0.010\end{array}$ & $\left.\right|^{38}$ \\
\hline $\begin{array}{l}11 \\
12 \\
13 \\
14 \\
15 \\
16\end{array}$ & 18 & 0.54 & $\begin{array}{c}1.5 \\
\mid\end{array}$ & 3700 & $\begin{array}{l}0.010 \\
0.005 \\
0.015 \\
0.015 \\
0.005 \\
0.010\end{array}$ & $\begin{array}{l}0.010 \\
0.005 \\
0.005 \\
0.015 \\
0.015 \\
0.010\end{array}$ & $\begin{array}{l}30 \\
1\end{array}$ \\
\hline $\begin{array}{l}17 \\
18 \\
19 \\
20 \\
21 \\
22\end{array}$ & 18 & 0.54 & $\begin{array}{c}3.0 \\
1\end{array}$ & 1850 & $\begin{array}{l}0.010 \\
0.010 \\
0.005 \\
0.015 \\
0.010 \\
0.010\end{array}$ & $\begin{array}{c}0.005 \\
0.015 \\
0.010 \\
\square\end{array}$ & $\begin{array}{c}30 \\
1 \\
15 \\
53\end{array}$ \\
\hline 23 & 18 & 0.54 & 1.5 & 3700 & 0.010 & 0.010 & 30 \\
\hline $\begin{array}{l}24 \\
25 \\
26 \\
27\end{array}$ & 9 & 0.54 & $i^{1.5}$ & $\begin{array}{c}7400 \\
\mid\end{array}$ & $\begin{array}{l}0.005 \\
0.015 \\
0.010 \\
0.010\end{array}$ & $\begin{array}{l}0.010 \\
0.010 \\
0.005 \\
0.005\end{array}$ & $\stackrel{30}{1}$ \\
\hline
\end{tabular}

Note that runs 11, 16, 23 are replicates. 
TABLE 3.-COMPARISON OF DIFFERENT WAVE ROTORS

\begin{tabular}{|c|c|c|c|c|c|c|}
\hline & Thayer & Weatherston & Pearson & Hoerler & Kenttield & This work \\
\hline Machine type & $\begin{array}{l}\text { Pressure } \\
\text { exchanger }\end{array}$ & $\begin{array}{l}\text { Pressure } \\
\text { exchanger }\end{array}$ & $\begin{array}{l}\text { Wave } \\
\text { turbine }\end{array}$ & $\begin{array}{l}\text { Pressure } \\
\text { exchanger }\end{array}$ & $\begin{array}{l}\text { Flow } \\
\text { divider }\end{array}$ & Flow divider \\
\hline Length-L" & 15.8 & 66 & 3.5 & 4.25 & 11 & 9.18 \\
\hline Diameter-D $D^{n}$ & 14.4 & 60 & 9 & 3.23 & 8 & 12 \\
\hline Passage width- $\mathrm{B}^{n}$ & 0.4 & 0.55 & 0.7 & 0.19 & 0.66 & $0.25,0.54$ \\
\hline Passage height- $H^{x}$ & 1.5 & 1.43 & $1 / 5$ & 1.1 & 2.2 & 0.4 \\
\hline Hydraulic dia- $D_{n}^{n}$ & 0.63 & 0.79 & 0.95 & 0.32 & 1.05 & $0.31,0.46$ \\
\hline RPM & 1960 & 2700 & 18000 & 11200 & 5.500 & $1850-7400$ \\
\hline Cycles/revolution $n$ & 2.5 & 1 & 1 & 2 & 3 & $1.5,3$ \\
\hline Leakage gap- $\delta$ & $0.004-0.013$ & & & 0.004 & 0.007 & $0.005,0.01,0.015$ \\
\hline Ratio LD & 25 & 84 & 3.7 & 13 & 10.5 & $20-58$ \\
\hline Ratio $2 \delta / H$ & $0.005-0.017$ & & & 0.007 & 0.006 & $0.025-0.075$ \\
\hline$\tau$ & 0.2 & 0.1 & 0.3 & 0.33 & 0.35 & $0.08-0.35$ \\
\hline
\end{tabular}

TABLE 4.-VALUES OF THE CONSTANTS IN EQUATION (13)

\begin{tabular}{|l|c|c|c|c|c|c|}
\hline Constant & $\mathrm{b}_{0}$ & $\mathrm{~b}_{3}$ & $\mathrm{~b}_{4}$ & $\mathrm{~b}_{11}$ & $\mathrm{~b}_{22}$ & $\mathrm{~b}_{12}$ \\
\hline Value & 0.42 & -1.18 & -0.56 & -1.30 & -1.74 & 0.70 \\
\hline
\end{tabular}




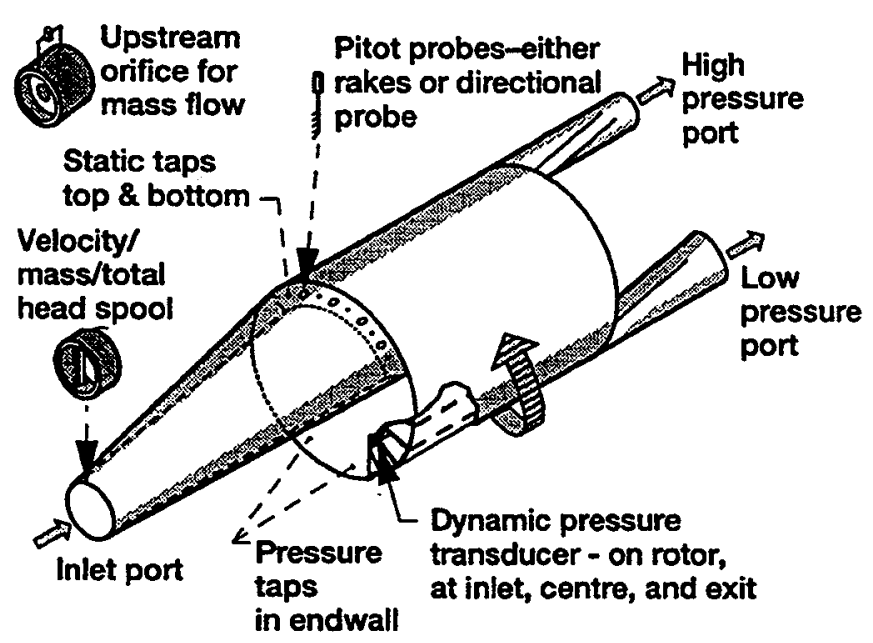

Figure 1.-Schematic diagram of the apparatus with the diagnostics used.

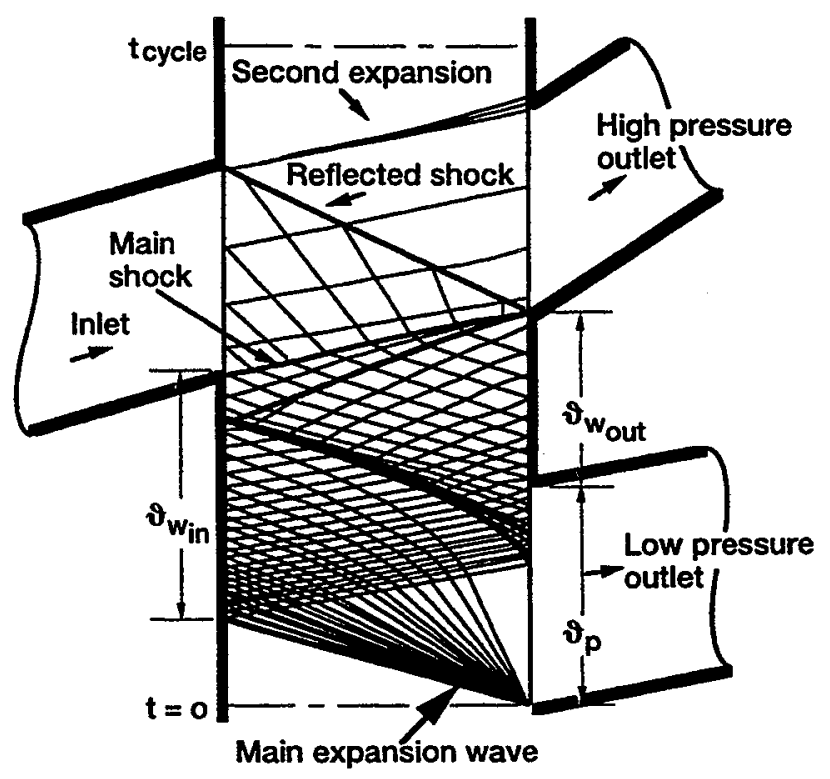

Figure 3.-Characteristics calculation of the flow divider cycle for $\epsilon=0.33$.
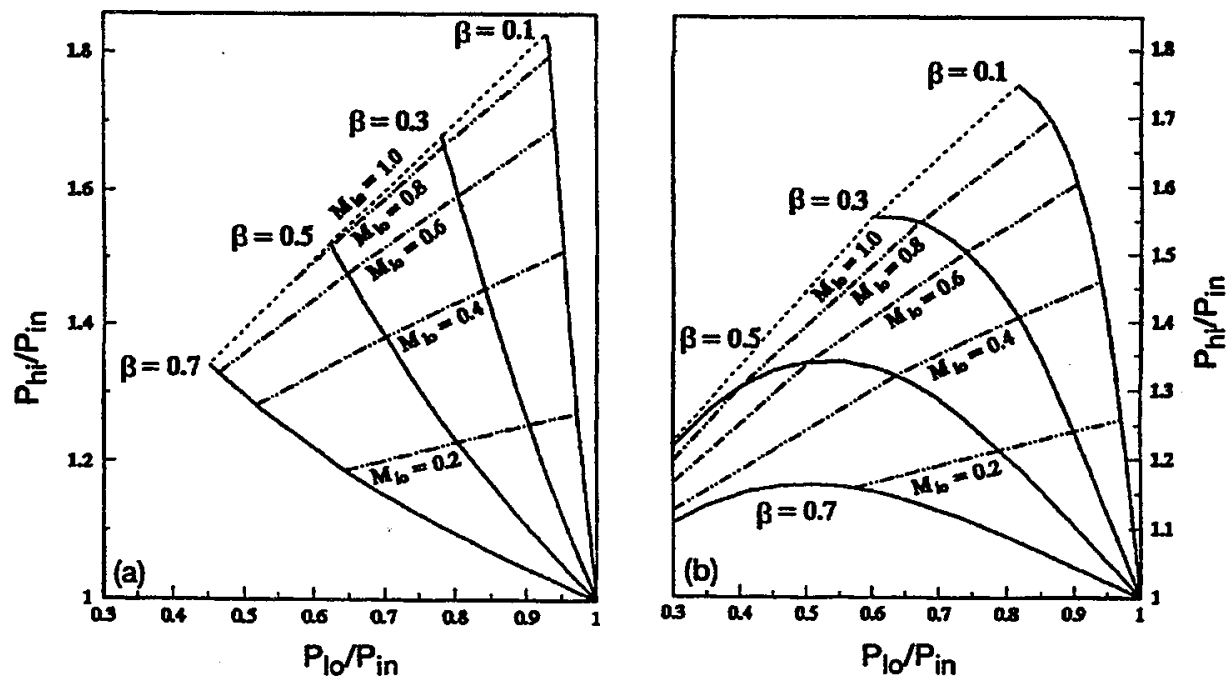

Figure 2.-Performance of a three-port flow divider calculated for (a) the isentropic cycle (left), and (b) the ideal cycle. 


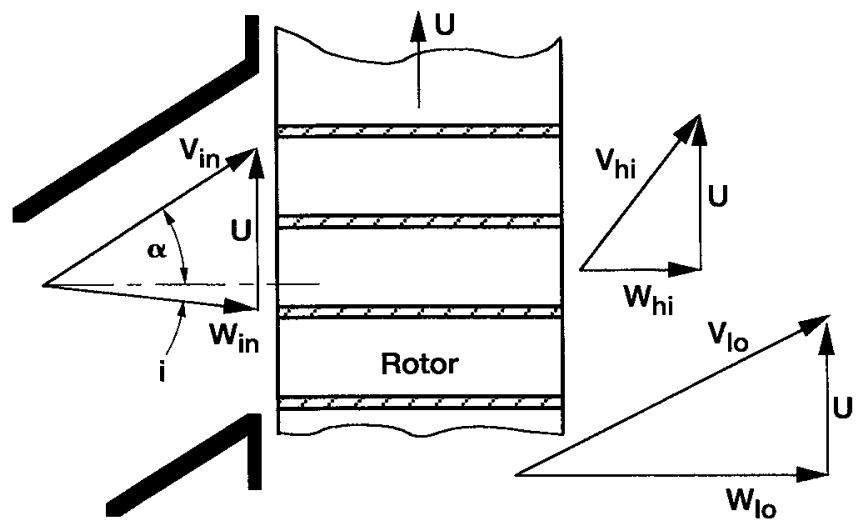

Figure 4.-Inlet and outlet velocity diagrams for the wave rotor.

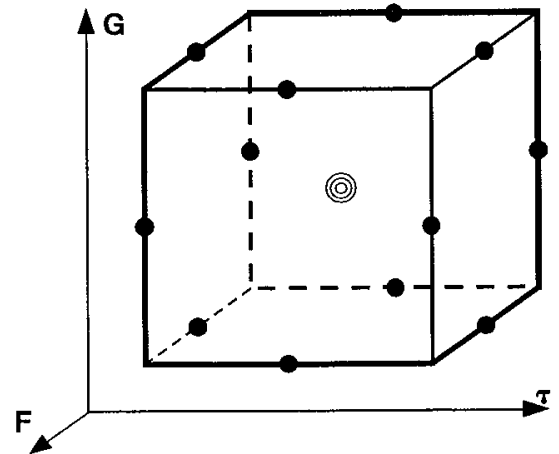

Figure 5.- -lliustration of the Box-Behnken design of an experiment for three variables. Runs are made at values of the variables corresponding to the solid circles shown. In addition the center point, indicated by the three concentric circles is repeated three times.

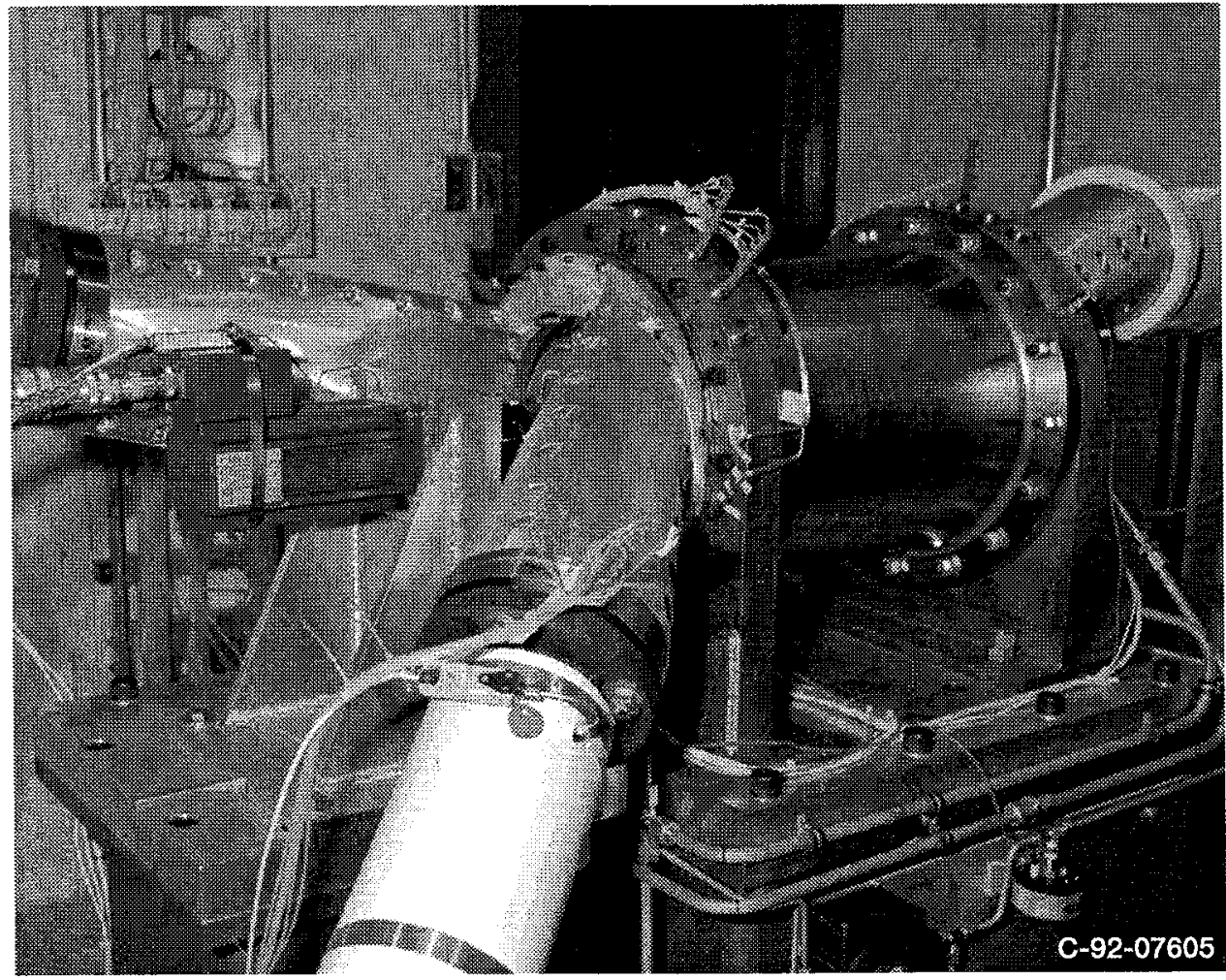

Figure 6.-A photograph of the three-port flow divider apparatus. 


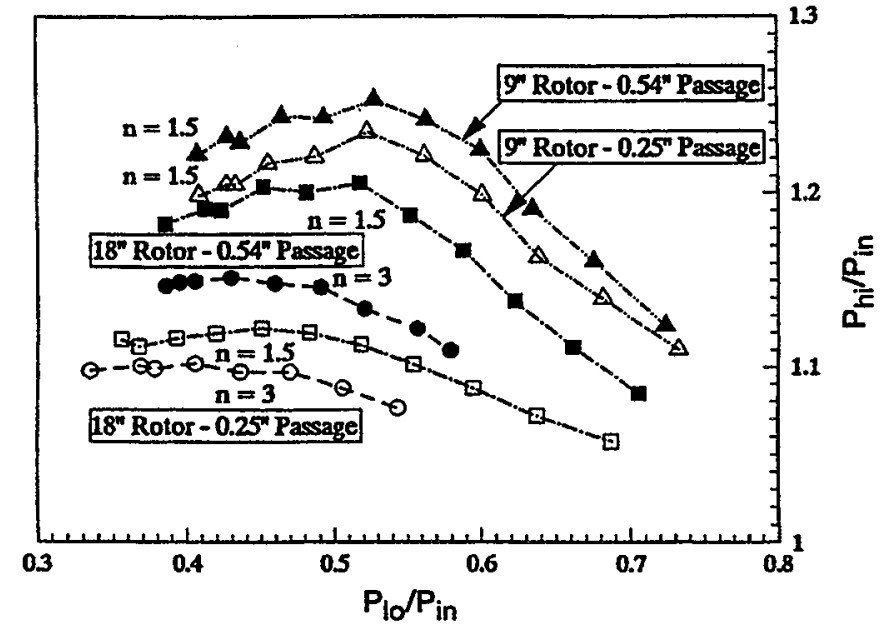

Figure 7.-A summary of the experimental results, showing the variation in performance with changes in opening time and passage length.

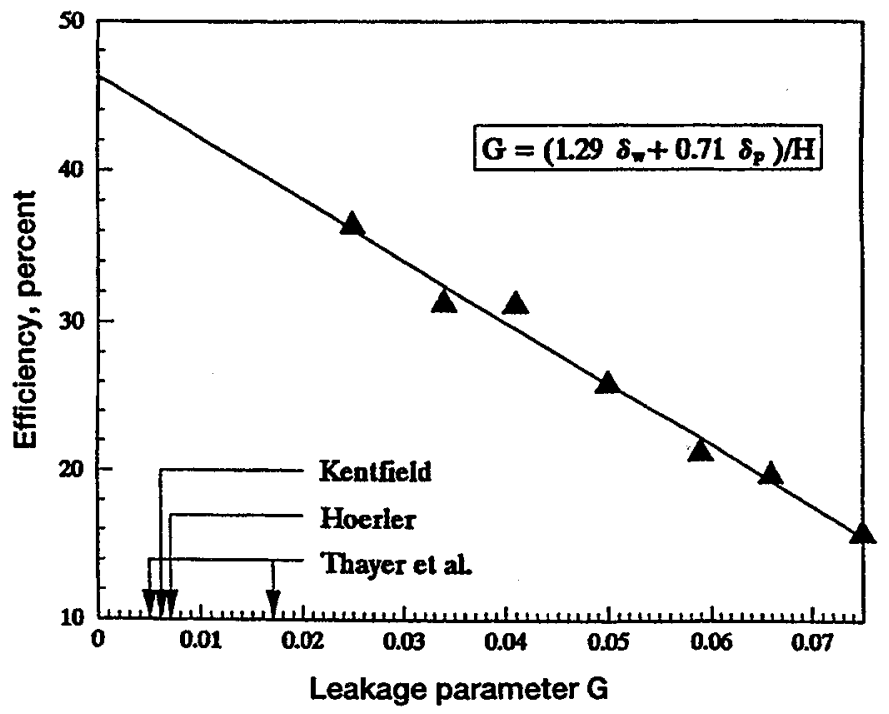

Figure 9.-Experimentally observed flow divider efficiency versus leakage parameter for the 9 " rotor, at an expansion ratio of $\mathbf{0 . 6}$.

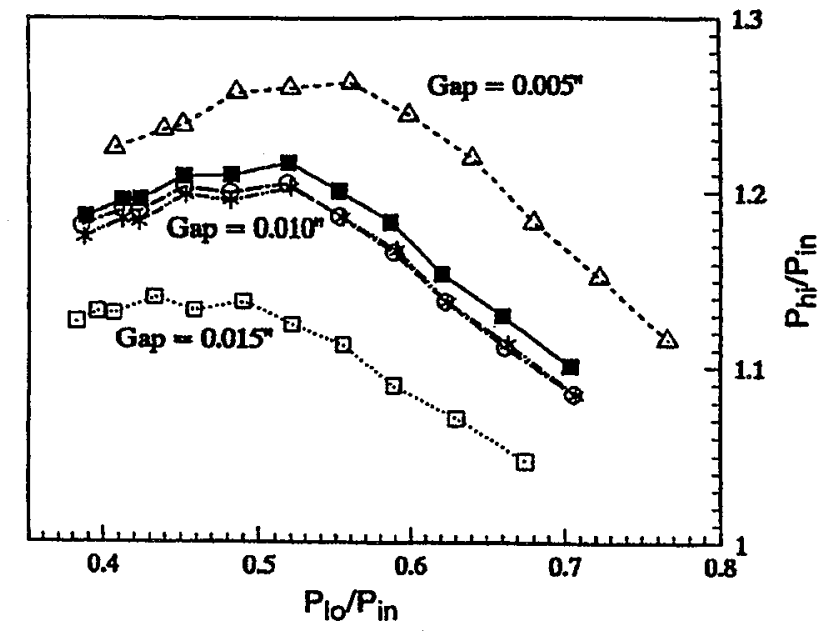

Figure 8.-A summary of the experimental results obtained while varying the leakage gap. Results for a gap of $0.010^{\prime \prime}$ represent the center point, which was run three times.

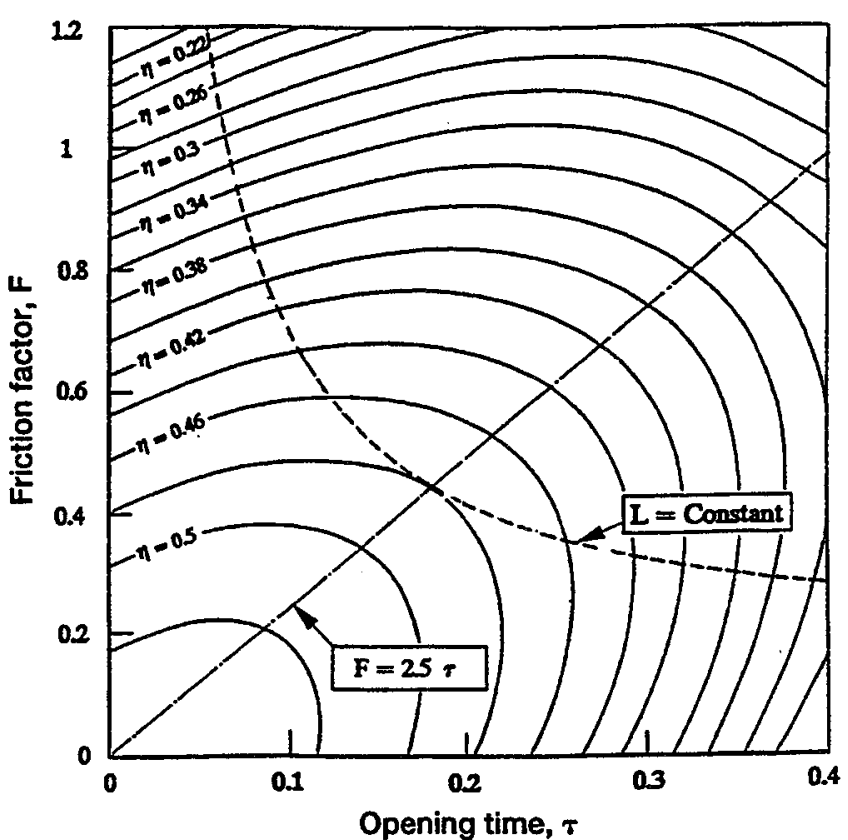

Figure 10.-Contour plots of flow divider efficiency as a function of opening time and friction factor, calculated with equation 22. 
Public reporting burden for this collection of information is estimated to average 1 hour per response. including the time for reviewing instructions, searching existing data sources,

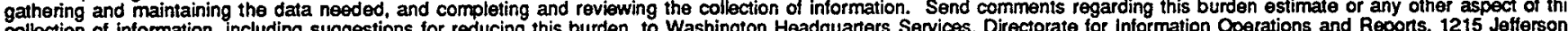
Davis Highway, Sutte 1204. Arlington. VA 22202-4302, and to the Office of Management and Budget, Paperwork Reduction Project (0704-0188), Washington. DC 20503.

\begin{tabular}{|l|l|l|}
\hline 1. AGENCY USE ONLY (Leave blank) & $\begin{array}{c}\text { 2. REPORT DATE } \\
\text { February } 1996\end{array}$ & $\begin{array}{r}\text { 3. REPORT TYPE AND DATES COVERED } \\
\text { Final Contractor Report }\end{array}$ \\
\hline
\end{tabular}

\section{TITLE AND SUBTITLE}

5. FUNDING NUMBERS

\section{An Experimental Determination of Losses in a 3-Port Wave Rotor}

WU-505-62-75

6. AUTHOR(S)

C-NAS3-27186

Jack Wilson

7. PERFORMING ORGANIZATION NAME(S) AND ADDRESS(ES)

NYMA, Inc.

2001 Aerospace Parkway

Brook Park, Ohio 44142

8. PERFORMING ORGANIZATION REPORT NUMBER

E-10079

9. SPONSORING/MONITORING AGENCY NAME(S) AND ADDRESS(ES)

10. SPONSORING/MONITORING AGENCY REPORT NUMBER

National Aeronautics and Space Administration

Lewis Research Center

NASA CR-198456

Cleveland, Ohio 44135-3191

\section{SUPPLEMENTARY NOTES}

Prepared for Turbo Expo '96 sponsored by the International Gas Turbine Institute of the American Society of Mechanical Engineers, Birmingham, UK, June 10-13, 1996. Project Manager, Kestutis C. Civinskas, Propulsion Systems Division, NASA Lewis Research Center, organization code 2760, (216) 433-3944.

12a. DISTRIBUTION/AVAILABILTYY STATEMENT

Unclassified - Unlimited

Subject Category 07

This publication is available from the NASA Center for Aerospace Information, (301) 621-0390.

13. ABSTRACT (Maximum 200 words)

Wave rotors, used in a gas turbine topping cycle, offer a potential route to higher specific power and lower specific fuel consumption. In order to exploit this potential properly, it is necessary to have some realistic means of calculating wave rotor performance, taking losses into account, so that wave rotors can be designed for good performance. This in turn requires a knowledge of the loss mechanisms. The experiment reported here was designed as a statistical experiment to identify the losses due to finite passage opening time, friction, and leakage. For simplicity, the experiment used a 3-port, flow divider, wave cycle, but the results should be applicable to other cycles. A $12^{\prime \prime}$ diameter rotor was used, with two different lengths, $9^{\prime \prime}$ and $18^{\prime \prime}$, and two different passage widths, $0.25^{\prime \prime}$ and $0.54^{\prime \prime}$, in order to vary friction and opening time. To vary leakage, moveable end-walls were provided so that the rotor to end-wall gap could be adjusted. The experiment is described, and the results are presented, together with a parametric fit to the data. The fit shows that there will be an optimum passage width for a given wave rotor, since, as the passage width increases, friction losses decrease, but opening-time losses increase, and vice-versa. Leakage losses can be made small at reasonable gap sizes.

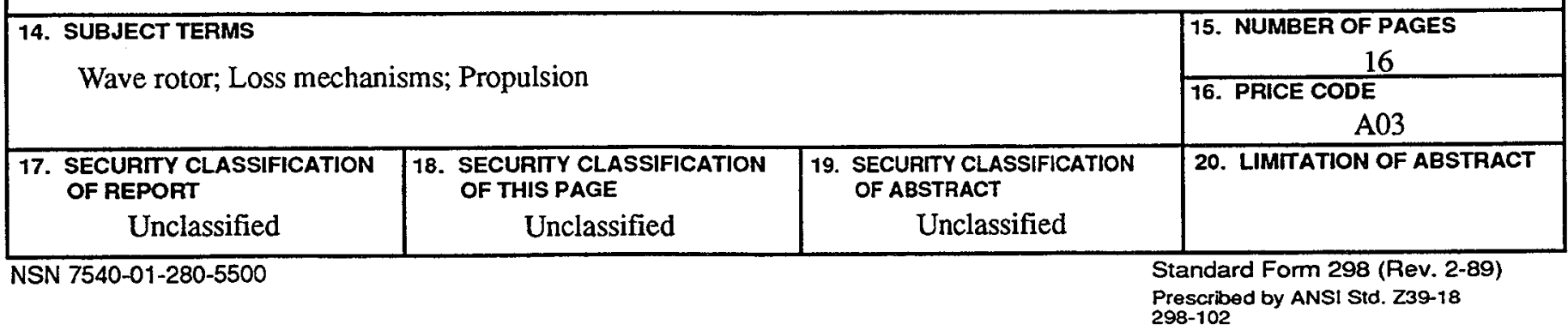


National Aeronautics and

Space Administration

Lewis Research Center

21000 Brookpark Rd.

Cleveland, $\mathrm{OH}$ 44135-3191

Official Business

Penalty for Private Use $\$ 300$

POSTMASTER: If Undeliverable — Do Not Return 